\title{
ASPECTOS SOCIAIS NA AVALIAÇÃO DE IMPACTOS DE CONSTRUÇÃO DE BARRAGENS EM AMBIENTES FLUVIAIS
}

\section{SOCIAL ASPECTS IN IMPACT ASSESSMENT OF DAMS CONSTRUTION IN RIVER ENVIRONMENTS}

\author{
Carlos Alberto de Oliveira Magalhães Júinior* \\ juniormagalhaes@hotmail.com \\ Joici de Carvalho Leite* \\ joicicarvalho@hotmail.com \\ Tânia do Carmo * \\ taniadocarmo_@hotmail.com \\ Adriano José Ortiz ** \\ adriano.ortiz@ifpr.edu.br \\ * Universidade Estadual de Maringá, Maringá/PR - Brasil \\ ** Instituto Federal do Paraná, Maringá/PR - Brasil
}

\section{Resumo}

A acelerada expansão das atividades que visam o desenvolvimento científico e tecnológico é norteada por meio da demanda e produção de energia, fator determinante para a prosperidade econômica e social de uma sociedade. No Brasil, país rico em recursos hídricos, a maior fonte de obtenção de energia elétrica é a utilização de águas fluviais. Nesta perspectiva, a partir da década de 1970 a construção de Usinas Hidrelétricas se tornou prioridade para o governo federal. Várias barragens foram projetadas e construídas em regiões onde moravam diversas famílias. Todas foram desterritorializadas e realocadas em outras regiões. Neste processo, tiveram que deixar junto à área inundada suas histórias de vida, costumes e culturas, para se adequar a nova realidade social. Os impactos sociais proporcionados no processo de construção de uma usina hidrelétrica é o foco deste artigo, que visa refleti-los com base em estudos já realizados por outros estudiosos da área. Vários fatores tanto positivos quanto negativos puderam ser repensados e assim permite-nos compreender alguns aspectos como a importância de envolver as pessoas que irão passar pela desapropriação do local onde moram, dando-lhes maiores e melhores condições de refazer sua reestruturação social.

Palavras-chave: recursos hídricos, desterritorialização, reestruturação social.

\begin{abstract}
The accelerated expansion of activities aimed at scientific and technological development is guided by energy demand and production, determining factor for economic and social prosperity of a society. In Brazil, a rich country in water resources, the main source of obtaining electricity is the use of river water. In this perspective, from the 1970s the construction of hydropower plants has become a priority for the federal government. Several dams were designed and built in regions where lived many families. All were dispossessed and relocated elsewhere. In this process, they had to leave the flood area along their life stories, customs and cultures, to suit the new social reality. Social impacts provided in a hydroelectric power plant construction process is the focus of this paper, which aims to reflect them based on previous studies by other researchers in the area. Several positive and negative factors could be rethought and this enables us to understand some aspects such as the importance of involving the people
\end{abstract} Revista Valore, Volta Redonda, I (I): I47-I58., Dezembro/2016 
who will go through the expropriation of where they live, giving them larger and better able to retrace their social restructuring.

Keywords: water resources, deterritorialization, social reestructuraction.

\section{1 - INTRODUÇÃO}

O desenvolvimento urbano e rural no Brasil tem provocado um aumento considerável na demanda de eletricidade nas últimas décadas. Entre 2013 e 2014, o consumo nacional sofreu um salto de 10.273 GWh, de 463.122 para 473.395 GWh. Em uma projeção de 10 anos, até 2024, o Ministério de Minas e Energia ainda indica um aumento de demanda de 220.074GWh (BRASIL, 2015).

Com isso, é necessário planejamento para aumentar a produção de energia e suprir necessidades econômicas e sociais numa era tecnológica que precisa de recursos energéticos para continuar seu desenvolvimento.

É comum perceber em relatórios e documentos oficiais uma ênfase na preocupação com as avaliações dos impactos que serão criados com a realização das obras, e muitas vezes tais avaliações se restringem mais em aspectos ambientais do que sociais. Inclusive podemos perceber que os protestos mais motivados vêm de ambientalistas e ecólogos preocupados com os impactos ambientais, em detrimento de impactos sociais.

Neste trabalho, tomamos como foco de investigação os aspectos sociais que geralmente ficam a margem das discussões referentes aos processos comumente encontrados em regiões de instalações hidrelétricas. Neste contexto "além dos aspectos técnicos e estruturais na construção de empreendimentos hidrelétricos, é relevante considerar aspectos subjetivos, humanos e simbólicos que precisam ser esclarecidos para a melhor gestão desses projetos” (DERROSSO; ICHIKAWA, 2014, p.97).

Desta forma, pretendemos com o presente estudo fazer algumas reflexões acerca das questões sociais impactadas devido à concepção de barragens e reservatórios em ambientes fluviais.

\section{2 - AS BARRAGENS FLUVIAS NO BRASIL}

De acordo com Amorim e Jesus (2006), o uso de energia hidroelétrica surge como alternativa a partir de 1885 nos EUA. Nos dias atuais estima-se que 60\% dos rios do mundo estejam represados, e que Revista Valore, Volta Redonda, I (I): I47-I58., Dezembro/2016 
aproximadamente 80 milhões de pessoas, de várias partes do mundo, foram desalojadas de suas casas para a construção de projetos hidrelétricos. E assim, ecossistemas foram dizimados com a implementação de mais de 45 mil hidroelétricas.

Para Colito (2000), a política energética do Brasil é um exemplo de política de inundação de terras e expulsão das populações. Os intensos investimentos nacionais em projeção e implantação de barragens foi uma realidade entre os anos de 1960 e 1980. A busca por produção de mais energia levou o país a construir mais de sessenta hidrelétricas, o que proporcionou o reconhecimento internacional do Brasil como um dos maiores investidores em projetos de grandes proporções para a produção de energia hidrelétrica (DERROSSO; ICHIKAWA, 2014).

Neste cenário que correspondia ao período político da Ditadura Militar, ocorreu um grande desenvolvimento da Engenharia Civil, e como consequência de diversas obras, um alto índice de desenvolvimento urbano. Para atender a essa demanda, houve a necessidade de projetos para: reservatórios de água, controle de enchentes e principalmente a geração de energia, com isso, foram construídas barragens, elevados e usinas termoelétricas, hidroelétricas e nucleares (TAKEUCHI, 2009). Desse modo, novos planos para a obtenção de energia em alta escala, passaram a fazer parte das prioridades do governo federal, como: usinas termoelétrcias e hidrelétricas (Ilha Solteira, Tucuruí I e II, Paulo Afonso, Jupiá, Porto Primavera, Itaipu); nucleares (Angra I e II) e de extração de Petróleo (refinaria da Petrobras) (THAUMATURGO; SIMÕES, TRANNIN, 2013).

A produção de energia por meio de recursos hídricos foi a mais utilizada pelo Brasil para proporcionar a oferta de eletricidade. Para isso, foram realizados grandes investimentos em construção de barragens e reservatórios para criação de Usinas Hidroelétricas de Energia (UHE), correspondendo $66,6 \%$ da capacidade instalada de geração elétrica (BRASIL, 2015).

Em terras nacionais brasileiras o processo de instalação de uma UHE é comumente defendido, por meio de justificativa estratégica de que o país possui uma grande oferta hídrica, assim têm elevada capacidade de desenvolvimento ao utilizar este recurso para a produção de energia, promovendo, consequentemente, o desenvolvimento social, político e econômico. Tal justificativa aportou o desenvolvimento de projetos de grande escala como Itaipu e Tucuruí (COLITO, 2000).

Como exemplo desta discrepância de riquezas entre elementos sociais e ambientais, pode-se citar a bacia do Amazonas que possui a maior parte (72\%) do potencial hidrelétrico inventariado pela Agência Nacional de Energia Elétrica (BRASIL, 2008).

Para o início de qualquer obra que irá envolver grandes impactos na estrutura socioambiental de uma região é obrigatória à realização de estudos sobre a área para obtenção das Licenças Ambientais. 
Estes documentos devem levar em conta, não apenas aspectos ambientais, mas também sociais, já que a sociedade como um todo será atingida. De acordo com Magalhães, Marin e Castro (2009, p. 29), em estudo realizado sobre a construção da UHE de Belo Monte “Os Estudos de Impactos Ambientais (EIA) subestima a população rural residente e distorce os dados mais elementares de caracterização de população, como: população economicamente ativa, profissão e pirâmide etária".

Também Soares (2009), ao estudar os impactos sociais causados pela construção da UHE Candonga, indaga que tais estudos não questionam o custo social da retirada das pessoas, que não tem outra escolha além de receber o dinheiro e reconstruir sua vida em outro lugar.

Queiroz (2011, p. 14-15) afirma que "os Estudos de Impacto Ambiental (EIA) não incluem os impactos socioambientais, redundando em ações mitigadoras e ou compensatórias tardias e insatisfatórias". Ainda de acordo com a autora:

As alterações no modo de vida estão associadas à inundação de áreas povoadas para formação do reservatório, provocando o deslocamento compulsório e a ruptura social; a mudança no bioma com interferência na cadeia alimentar e alteração nos processos de produção nativa de base agroextrativista e na caça (p. 14).

Magalhães, Marin e Castro (2009), relata que a construção da Usina é responsável por alagar e reduzir a oferta de água em um trecho de $100 \mathrm{~km}$ em volta do grande Rio Xingu, que banha dezenas de comunidades além de terras indígenas. Somado a tudo isso, existem impactos sobre fauna e flora aquática em geral e subestimação da população atingida, sobretudo a indígena que depende das terras atingidas. Outro ponto destacado por Magalhães, Marin e Castro $(2009$, p. 67) é a modificação da vazão do Rio Xingu: "provocando um estado de diminuição do lençol freático, mudanças nos trechos navegáveis, importante perda de fauna aquática e terrestre, escassez de água, etc”.

Couto e Silva (2009, p. 88), discorrem que não existe um diagnóstico da questão da saúde da população de referência para o empreendimento da Usina de Belo Monte. Para os autores, "há uma referência a dados secundários, não confiáveis, por não representarem a realidade”. Autores como Santos et al. (2012) relatam que existe uma tentativa, desde a segunda metade do século XX, de implementar uma "civilização" na região amazônica. Ainda segundo esses autores, a construção de Belo Monte gerará aproximadamente 20 mil empregos diretos e diversos empregos indiretos na região do Xingu, ou seja, um grande contingente de trabalhadores vindos de diversas partes do Brasil para trabalharem as margens do Rio Xingu, gerando um alto impacto populacional na região.

Com relação à Usina Hidrelétrica de Estreito no Rio Tocantins, sua construção atingiu principalmente o município de Babaçulândia, impactando diretamente comunidade e ecossistema, e em 
especial o povoado de Palmatuba, que desenvolvia basicamente: agropecuária (cria, recria e gado leiteiro), criação de pequenos animais, lavouras de subsistência, produção artesanal de artefatos cerâmicos (tijolos e telhas), coleta e beneficiamento da amêndoa de Babaçu para a produção de óleo comestível e produtos artesanais como: brincos, pulseiras, cintos, bolsas, chaveiros, (AMORIM; JESUS, 2006). Com a inundação do povoado, os impactos ambientais e sociais na população são devastadores, porém, vão além, "pois afetam os meios produtivos, elaborados durante mais de um século de dominação da natureza e de sobrevivência na região e que com o enchimento do lago se tornarão inviáveis" (AMORIM; JESUS, 2006, p. 22). Assim, os autores exemplificam:

1. O sistema de agricultura de vazante que aproveita a fertilização que as cheias regulares fazem nas margens do rio para produzir mais e com menor esforço.

2. A pesca artesanal em pequenas embarcações e mesmo nas ribanceiras do rio, que será afetada pela inviabilidade de navegação com pequenas canoas e com a redução das populações de peixes migratórios que são as populações íctias tradicionais do Rio Tocantins.

3. O extrativismo, cuja viabilidade de exploração será enormemente comprometida.

Desta forma, retomamos Queiroz e Motta-Veiga (2012, p. 1392) que ressaltam que o custo social de empreendimentos hidrelétricos se reflete nos indicadores sociais da região, que no caso das regiões brasileiras são:

[...] elevados índices de pobreza expressos no status quo da educação, saúde, saneamento, habitação e trabalho das áreas afetadas. O processo de desapropriação e relocação causam impactos nas atividades de subsistência, sobretudo, para aqueles intimamente ligados à vida ribeirinha com base na agricultura, caça, pesca e extração vegetal. Este processo foi agravado pela dinâmica demográfica e social, observada pelo deslocamento migratório das populações atraídas pelo empreendimento.

Nessa perspectiva, é possível compreender o posicionamento de autores como Colito (2000) e Soares (2009) quando afirmam que há uma assimetria de poder nos embates causados pela construção de hidrelétricas em todo o país. Se de um lado temos uma população que não pode ir contra a determinação de órgãos especializados do governo, que não consideram em suas avaliações tecnocratas as referências construídas e as relações estabelecidas pela comunidade ao longo dos anos, de outro temos empresas que, justificadas pela demanda energética nacionais, apossam-se de bens públicos, como rios e cachoeiras e passam a explorá-lo para interesses privados.

Reafirmamos que Belo Monte e Estreito são apenas dois exemplos, mais atuais, dos impactos sociais que a construção de barragem fluvial provoca nas populações ribeirinhas, sendo que esses já possuem toda uma identidade que foi construída a partir de memórias projetadas sob os acontecimentos e lugares e relações sociais com vizinhos e com a natureza. 


\section{3 - DESENVOLVIMENTO}

Tomando como ponto de partida os aspectos sociais que de alguma forma passam por transformações, sejam elas de caráter satisfatório ou não pela sociedade que lá vive, abordaremos algumas reflexões sobre estas mudanças no comportamento social.

O processo de mudança nos aspectos sociais de determinada região que irá abrigar uma EHE tem início com os estudos para a obtenção da Licença Ambiental. Segundo Derrosso e Ichikawa (2014, p. 98), "É nesse momento, de construção da barragem, que começam os principais problemas ambientais e sociais, pois uma grande área de terra (na maioria das vezes, produtiva) será alagada e todo sistema social e ecológico será destruído para sempre”.

Neste contexto de mudança devido à instalação da hidrelétrica, várias podem ser as visões a respeito das transformações ocorridas no meio socioambiental, podendo ser citados efeitos negativos referentes a aspectos sociais como: perdas de heranças históricas e culturais; alterações em atividades econômicas; problemas de saúde pública, devido à deterioração ambiental e efeitos sociais por realocação (CARREGARO; PERIUS, 2012).

Mas também são proporcionadas mudanças sociais positivas que se fazem importantes como: criação de possibilidades de recreação e turismo; melhoria da navegação e transporte; aumento da população de peixe e da possibilidade de aquicultura; regulação do fluxo e consequentemente menor chance de inundações; maiores possibilidades de trabalho para a população local (CARREGARO; PERIUS, 2012), geração de royalties para os municípios (REBOUÇAS; BRAGA, 2002).

Apesar de não muito explícito, as mudanças sociais começam a ocorrer a partir do planejamento da obra ocasionando alterações para o meio social regional. A chegada de Engenheiros, Arquitetos, Administradores, Economistas, Biólogos, entre outras classes de profissionais interferem e influenciam na sociedade local, seja pelo aspecto econômico ou pelo aspecto sociocultural. Exemplo disso, podemos citar o trabalho de Thaumaturgo, Simões e Trannin (2013), referente ao impacto sobre a urbanização causado no processo de construção da usina de Itaipu iniciada na década de 1970. De acordo com os autores (p. 984)

A cidade não estava devidamente preparada para receber uma população de aproximadamente 40.000 operários com suas respectivas famílias, vinda de vários estados do país para a construção da usina. Aliado à vinda desses operários, novas estradas, hospitais, escolas, condomínios residenciais, estabelecimentos comerciais, mudança de hábitos e costumes diferentes da população local. Enfim, uma nova infraestrutura foi criada para atender a esta população vinculada à construção daquela que era considerada a maior usina hidrelétrica do mundo. 
Neste cenário, de novas instalações socioculturais, socioeconômicas e sociopolíticas, na vida de quem está chegando à cidade e de quem está recebendo toda esta nova população, são sentidas e vivenciadas novas experiências e transformações de costumes, saberes e novas concepções de identidade. Derrosso e Ichikawa (2014, p. 99) utilizando Habermas (2009), ressaltam:

que o conceito de identidade faz referência ao indivíduo como sendo capaz de construir novas identidades a partir de identidades fragmentadas ou superadas, mas que se tornam de tal maneira integradas, que o tecido das interações se organiza na forma de uma biografia que pode ser atribuída como sua.

Isso devido à instalação dos operários, que muitas vezes movimentam o mercado imobiliário local ou, em outras vezes, criam novos bairros ou cidades, conduzindo ao aumento significativo de todo o comércio, uma vez que na maioria destas obras, a região não oferta mão de obra qualificada suficiente para completar todas as vagas necessárias para suas execuções, sendo necessário trazer empregados de outras regiões.

Então, além da criação de novos empregos para a comunidade local, também há a chegada de novos cidadãos para ocupar aquelas vagas ociosas. Com isso, não somente a influência cultural e econômica passa sofrer impactos, mas, também, o modo de vida e costumes sociais passa sofrer sérias modificações, como, o início e/ou agravamento de doenças, da prostituição, escassez de produtos, etc.

Durante o enchimento do reservatório podemos citar outros impactos, como o abandono forçado de terras e casas (MENDES, 2005), a mudança de meio de sustento, alteração da paisagem gerando conflito na identidade visual do local (AGUILAR, 2006), a perda dos laços comunitários e até mesmo uma interferência na identidade cultural (IHA, 2004).

Queiroz (2011), ao analisar os impactos sociais de grandes empreendimentos hidrelétricos como UHE James Bay, localizados na região da cidade de Québec, povoados por várias etnias indígenas, constatou que junto ao processo de reacomodação, as mudanças ocorreram em meio a problemas sociais como abuso de álcool e droga, depressão, suicídio, violência e aculturação.

Muitos foram os aspectos negativos que assolaram os povos indígenas da região de Québec, onde a UHE foi instalada e os principais impactos sociais negativos foram:

a desagregação social, associada à rápida desintegração do modo de vida tradicional; além dos aspectos de saúde, decorrentes das mudanças sociais sem planejamento, externamente induzida pelo processo de urbanização, derivados do grande fluxo migratório e da relocação da comunidade (QUEIROZ, 2011, p. 38). 
Neste sentido, é importante que a sociedade seja consultada durante a elaboração e execução do projeto e faça parte das decisões a serem tomadas, minimizando, em parte, suas perdas, e colocando seus interesses em discussão. Aguilar (2006) relata que para isso ocorrer é necessário que empreendedores e população entrem em acordo, procurando minimizar os conflitos.

A fase de enchimento e até mesmo a manutenção do fluxo a jusante pode apresentar riscos à saúde humana, trazendo doenças associadas às águas paradas e alimentos contaminados (exemplo de contaminação de peixes por mercúrio), como UHE - São Manuel (2011).

Terminada a fase de enchimento, a abundância de peixes acarreta numa oferta de emprego para a comunidade local, induzindo vários ribeirinhos a se especializarem em pesca doméstica e passando a ser seu próprio meio de sustento.

Nesta fase podemos notar com maior ênfase a mudança na paisagem da região, gerando muitas ilhas e também praias, o que tende a provocar uma predisposição ao ecoturismo, atraindo banhistas e pescadores. A reestruturação do comercio começa a aparecer, mostrando mais restaurantes, bares e hotéis para melhor atender aos visitantes.

Estudos ecológicos mostram que, em geral, os primeiros anos após o represamento apresentam aumento na produtividade de pesca, ocorrendo devido a fatores como: o aumento da produtividade primária provocado pela liberação de nutrientes na coluna de água, aumentando o número de peixes planctívoros e insetívoros atraídos perto da barragem pela disponibilidade de alimento; obstáculos impostos pela barragem a determinados cardumes, havendo concentração de peixes no local, e atração de peixes piscívoros, dada a concentração de peixes pequenos (AGOSTINHO, GOMES, PELICICE, 2007).

Neste sentido, a pesca acaba se tornando muito viável para comunidades que se encontram a montante do reservatório, prejudicando consideravelmente, aquelas que vivem a jusante, uma vez que a construção da barragem ocasiona e o aumento na pesca a montante diminui bruscamente o número de peixes que descerão o rio após o reservatório.

Contudo, após alguns anos o rendimento de pesca começa a diminuir, uma vez que a produtividade geral cai ocasionada pela queda de nutrientes na água, como, também, a turbidez diminui deixando a coluna de água com mais entrada de luz. Este último fator acaba se tornando favorável para espécies predadoras, aumentado seu número de indivíduos, mas prejudicando as presas, levando em alguns casos a extinção de espécies.

A concentração de nutrientes no reservatório pode provocar um problema à parte, a eutrofização, situação na qual muitos reservatórios no mundo já passaram, sofrendo com a perda da 
qualidade da água e baixa na capacidade de abastecimento e recreação para a população e, também, para a manutenção da vida aquática (CARDOSO, 2011).

Outros aspectos que afetam a pesca regional são destacados por Agostinho, Gomes e Pelicice (2007) como sendo a baixa taxa de reprodução de várias espécies, causada pela mudança no ambiente; as mudanças bruscas no nível de água do reservatório ocorridas pelos procedimentos operacionais e; o elevado empenho de pesca aplicado no período de maior produtividade. Assim, depois do período de alto rendimento, ocorre um decréscimo na produção pesqueira, afetando a vida socioeconômica de muitos na região.

Agostinho e Zalewski (1996) relataram que a pesca em reservatório e no segmento do rio a montante da barragem tem servido como refúgio para várias famílias que não encontram seu sustento em outros setores da sociedade. Entretanto, fatores de alternância no reservatório provocam quedas consideráveis na produtividade de pesca e impacta diretamente a vida das famílias de pescadores que fizeram da atividade uma profissão.

Não somente a pesca profissional acaba sendo interferida, mas, também, a pesca do turismo. O turismo em geral também pode ser afetado com o processo de transporte de sedimentos sendo impedido pelas barragens. Neste caso o agravamento é maior em barragens sucessivas, ou seja, construção de barragens num mesmo rio ou bacia, onde uma barragem pode deixar de liberar sedimentos para jusante, e dessa forma tanto os trechos do rio como a barragem sucessiva acabarão se tornando mais profundos e perdendo suas praias, essas que são atração para os turistas banhistas.

\section{4 - CONSIDERAÇÕES FINAIS}

Ao passo que a demanda nacional por energia aumenta, projetos de criação de barragens e reservatórios entram em execução. Esses projetos acabam se implantando em algumas regiões do país, mas, em geral, acabam beneficiando uma grande parcela da população no cenário nacional.

Todavia, vários impactos são causados, sejam eles naturais, econômicos, locais ou globais. No aspecto social, podem alcançar membros de uma família por gerações, tanto numa esfera cultural, ambiental e, também, social, mudando hábitos, ensinamentos, valores culturais e morais, negócios e meio de sustento.

Suscitamos até então, que desde o planejamento da obra até sua execução, várias alterações sociais podem ser diagnosticadas. Assim, precisa-se considerar além dos aspectos ambientais (alteração da biodiversidade, mudanças climáticas, eutrofização, sedimentação, etc.); aspectos econômicos (custo e 
benefício da obra, economia regional, vida útil do reservatório, desapropriação, etc.); também os aspectos sociais.

Desta forma, necessita-se de mais estudos e interesse pelas questões sociais envolvendo esses projetos e as populações diretamente envolvidas nessa trama, a fim de minimizar os impactos prejudiciais na vida dessas famílias, considerando suas aspirações mediante as futuras mudanças.

\section{REFERÊNCIAS}

AGOSTINHO, C. S.; ZALEWSKI, M. A planície alagável do alto rio Paraná: importância e preservação. Maringá: Eduem, 1996.

AGOSTINHO, C. S.; GOMES, L. C.; PELICICE, F. M. Ecologia e manejo de recursos pesqueiros em reservatórios do Brasil. Maringá: Eduem, 2007.

AGUILAR, G. T. Avaliação de Impacto Social e proposição de medidas mitigadoras - Compromisso com a Responsabilidade Social, PCH Notícias \& SHP News,Ano: 8 / Set./Out./Nov., 2006.

BRASIL. Agência Nacional de Energia Elétrica. Atlas de energia elétrica do Brasil. Brasília : Aneel, 2008. p. 236p.BRASIL, Ministério de Minas e Energia. Resenha Energética Brasileira: Exercício de 2014. Brasília-DF, 2015. Disponível em: http://www.mme.gov.br/documents/1138787/1732840/

Resenha+Energ\%C3\%A9tica+-+Brasil+2015.pdf/4e6b9a34-6b2e-48fa-9ef8-dc7008470bf2. Acesso em: 29 de jun. de 2016.

BRASIL. Projeção da demanda de energia elétrica para os próximos 10 anos (1015-2024). Rio de Janeiro, 2015. Disponível em: http://www.epe.gov.br/mercado/Documents/DEA\%2003-2015\%20Projeções\%20da\%20Demanda\%20de\%20Energia\%20Elétrica\%202015-2024.pdf. Acesso em: 03 Julho 2016.

CARDOSO, E. T. S. Avaliação do grau de trofia e da qualidade da água de um braço do reservatório de Itaipu - Brasil. 2011. 144 p. Dissertação de Mestrado. UFABC - Santo André, 2011.

COLITO, M. C. E. A construção de usinas hidrelétricas e os impactos sobre a população e o espaço: comunidades rurais ameaçadas pela U.h. de Jataizinho - Rio Tibagi/Pr. Serviço Social em Revista. v.2, n.2. 2000 .

COUTO, R. C. S.; SILVA, J. M. As questões de saúde no estudo de impacto ambiental do Aproveitamento Hidroelétrico Belo Monte. . In: Painel de Especialistas: Análise Crítica do Estudo de Impacto Ambiental do Aproveitamento Hidrelétrico de Belo Monte, International Rivers, 2009, p. 81-90.

DERROSSO, G.S.; ICHIKAWA, E.Y. A Construção de uma usina hidrelétrica e a reconfiguração das identidades dos ribeirinhos: um estudo em Salto Caxias, Paraná. Ambiente \& Sociedade, v. XVII, n. 3 , p. $97-114$ n jul.-set. 2014.

FIGUEIRÊDO, M. C. B. et al. Avaliação da vulnerabilidade ambiental de reservatórios à eutrofização. Eng. sanit. ambient.V..12 - no 4 - out/dez 2007, 399-409. 
IHA (International Hidropower Association). Diretrizes de Sustentabilidade. Fev. de 2004. Disponível em:

$<$ http://www.hydropower.org/downloads/IHA\%20Sustainability\%20Guidelines_PORTUGUESE.pdf $>$ Acesso em: 26 de jan. 2009.

MAGALHÃES, S.; MARIN, R. A.; CASTRO, E . Análise de situações e dados sociais, econômicos e culturais. In: Painel de Especialistas: Análise Crítica do Estudo de Impacto Ambiental do Aproveitamento Hidrelétrico de Belo Monte, International Rivers, 2009, p. 23-35.

MENDES, N.A.S. As usinas hidrelétricas e seus impactos: os aspectos socioambientais e econômicos do Reassentamento Rural de Rosana - Euclides da Cunha Paulista. Dissertação apresentada ao Programa de Pós-graduação em Geografia da Faculdade de Ciências e Tecnologia - FCT/UNESP, Campus de Presidente Prudente, 2005.

PERIUS, M.R.; CARREGARO, J.B. Pequenas centrais hidrelétricas como forma de redução de impactos ambientais e crises energéticas. Ensaios e Ciência, Ciências Biológicas Agrárias e da Saúde, v. 16, n. 02, 2012.

QUEIROZ, A.R.S. Análise dos impactos sociais de grandes empreedimentos hidrelétricos: o caso do AHE Belo Monte". 2011. 74f. Dissertação (Mestrado). Escola Nacional de Saúde Pública, Sergio Arouca (ENSP), Fundação Oswaldo Cruz. Rio de Janeiro. 2011.

QUEIROZ, A. R. S.; MOTTA-VEIGA, M.Análise dos impactos sociais e à saúde

de grandes empreendimentos hidrelétricos: lições para uma gestão energética sustentável. Ciência \& Saúde Coletiva, n. 17, v. 6, 2012, p.1387-1398.

REBOUÇAS, A.C.; BRAGA, B. Ecossistemas de Águas Interiores. In. REBOUÇAS. A.C.; BRAGA, B.; TUNDISI, J.G. 2002. Águas Doces no Brasil - Capital Ecológico, uso e Conservação. São Paulo: Escrituras, 2002. 704p.SANTOS, T.; SANTOS, L.; ALBUQUERQUE, R.; CORREAA, E. Belo Monte: impactos sociais, ambientais, econômicos e políticos. Revista de la Facultad de Ciencias Económicas y Administrativas.Universidad de Nariño. v. 13, n. 2. Jul./Dez. 2012, p.214-227.

SOARES, V.R. Impactos Sociais causados pela construção de hidrelétricas em populações ribeirinhas na zona da mata mineira: o caso específico da Usina Hidrelétrica Candonga - Rio Doce/Santa Cruz Escalvado - Minas Gerais. Monografia (Ciências Sociais) - Instituto de Ciências Humanas, Universidade Federal de Juiz de Fora, Juiz de Fora, 2009.

TAKEUCHI, K. Least marginal environmental impact rule for reservoir development. Hydrological Sciences Journal, v.42, p. 583-597. London, UK, 2009. Disponível em: <http://www.tandfonline.com/ doi/abs/10.1080/02626669709492055> Acesso em: 01 de jul.2016.

THAUMATURGO, L. R. Y.; SIMÕES, S. J. C.; TRANNIN, I. C. B. A construção da usina hidrelétrica de Itaipu e seu impacto sobre a urbanização de Foz do Iguaçu. In: XVI SIMPÓSIO BRASILEIRO DE SENSORIAMENTO REMOTO - SBSR, 2013, Foz do Iguaçu, Anais ... Foz do Iguaçu, 2013. P 983990. Disponível em: <http://www.dsr.inpe.br/sbsr2013/files/p1519.pdf>. Acesso em: 01 de jul. 2016. 
UHE - SÃO MANOEL. Relatório de Impacto Ambiental: RIMA. 2011. Disponível em: $<$ http://www.epe.gov.br/MeioAmbiente/Documents/Rimas/Rima\%20$\% 20$ UHE\%20S\%C3\%A3o\%20Manoel.pdf>. Acesso em: 04/07/2016.

Recebido em: 05/07/2016

Aceito em: 03/08/2016

Nome: Carlos Alberto de Oliveira Magalhães Júnior

email: juniormagalhaes@hotmail.com

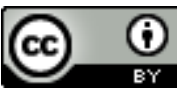

Este obra está licenciada com uma Licença Creative Commons Atribuição 4.0 Internacional. 